\title{
Cannabinoid Antagonist Drug Discrimination in Nonhuman Primates
}

\author{
Brian D. Kangas, Ani S. Zakarian, Kiran Vemuri, Shakiru O. Alapafuja, Shan Jiang, \\ Spyros P. Nikas, Alexandros Makriyannis, and Jack Bergman
}

Department of Psychiatry, Harvard Medical School, Boston, Massachusetts (B.D.K., J.B.); Behavioral Biology Program, McLean Hospital, Belmont, Massachusetts (B.D.K., A.S.Z., J.B.); and Center for Drug Discovery, Northeastern University, Boston, Massachusetts (K.V., S.O.A., S.J., S.P.N., A.M.)

Received July 29, 2019; accepted October 21, 2019

\begin{abstract}
Despite a growing acceptance that withdrawal symptoms can emerge following discontinuation of cannabis products, especially in high-intake chronic users, there are no Food and Drug Administration (FDA)-approved treatment options. Drug development has been hampered by difficulties studying cannabis withdrawal in laboratory animals. One preclinical approach that has been effective in studying withdrawal from drugs in several pharmacological classes is antagonist drug discrimination. The present studies were designed to examine this paradigm in squirrel monkeys treated daily with the long-acting $\mathrm{CB}_{1}$ agonist AM2389 $(0.01 \mathrm{mg} / \mathrm{kg})$ and trained to discriminate the $\mathrm{CB}_{1}$ inverse agonist/antagonist rimonabant $(0.3 \mathrm{mg} / \mathrm{kg})$ from saline. The discriminative-stimulus effects of rimonabant were both dose and time dependent and, importantly, could be reproduced by discontinuation of agonist treatment. Antagonist substitution tests with the $\mathrm{CB}_{1}$ neutral antagonists $\mathrm{AM} 4113(0.03-0.3 \mathrm{mg} / \mathrm{kg})$, AM6527 (0.03-1.0 mg/kg), and AM6545 (0.03-1.0 mg/kg) confirmed that the rimonabant discriminative stimulus also could be reproduced by $\mathrm{CB}_{1}$ antagonists lacking inverse agonist action. Agonist substitution tests with the phytocannabinoid $\Delta^{9}$-tetrahydrocannabinol $(0.1-1.0 \mathrm{mg} / \mathrm{kg})$, synthetic $\mathrm{CB}_{1}$ agonists nabilone $(0.01-0.1 \mathrm{mg} / \mathrm{kg})$, AM4054 $(0.01-0.03 \mathrm{mg} / \mathrm{kg})$, K2/Spice compound JWH-018 (0.03-0.3 mg/kg), FAAH-selective
\end{abstract}

inhibitors AM3506 (0.3-5.6 mg/kg), URB597 (3.0-5.6 mg/kg), and nonselective FAAH/MGL inhibitor AM4302 (3.0-10.0 mg/kg) revealed that only agonists with $\mathrm{CB}_{1}$ affinity were able to reduce the rimonabant-like discriminative stimulus effects of withholding daily agonist treatment. Although the present studies did not document physiologic disturbances associated with withdrawal, the results are consistent with the view that the cannabinoid antagonist drug discrimination paradigm provides a useful screening procedure for examining the ability of candidate medications to attenuate the interoceptive stimuli provoked by cannabis discontinuation.

\section{SIGNIFICANCE STATEMENT}

Despite a growing acceptance that withdrawal symptoms can emerge following the discontinuation of cannabis products, especially in high-intake chronic users, there are no FDAapproved pharmacotherapies to assist those seeking treatment. The present studies systematically examined cannabinoid antagonist drug discrimination, a preclinical animal model that is designed to appraise the ability of candidate medications to attenuate the interoceptive effects that accompany abrupt cannabis abstinence.

\section{Introduction}

In recent years, it has become commonly accepted that withdrawal symptoms can emerge following the abrupt discontinuation of cannabis products, especially in high intake

This research was supported by the National Institutes of Health National Institute on Drug Abuse [Grants R01-DA047575, P01-DA009158, R21-DA045882].

https://doi.org/10.1124/jpet.119.261818. chronic users. These evolving views were codified in the DSM5 (American Psychiatric Association, 2013) with the inclusion of Cannabis Use Disorder which, for the first time, included diagnostic criteria for cannabis dependence. Symptom categories following abrupt discontinuation include disturbances in mood, sleep, food consumption, and physical comfort (Budney and Hughes, 2006; Schlienz et al., 2017). It is widely recognized that such withdrawal discomfort can lead to relapse to cannabis use for symptomatic relief, presenting a formidable obstacle to successful (or long-term) remission.

ABBREVIATIONS: AM2389, 9 $\beta$-hydroxy-3-(1-hexyl-cyclobut-1-yl)-hexahydrocannabinol; AM3506, 5-(4-hydroxyphenyl)pentanesulfonyl fluoride; AM4054, 9 $\beta$-(hydroxymethyl)-3-(1-adamantyl)-hexahydrocannabinol; AM4113, 5-(4-alkylphenyl)-1-(2,4-dichlorophenyl)-4-methyl- $N$-(piperidin-1-yl)-1H-pyrazole-3-carboxamide; AM4302, 3-cyanophenyl 4-benzylpiperidine-1-carboxylate; AM6527, 5-(4-alkylphenyl)-1-(2,4dichlorophenyl)-4-methyl- $N$-(morpholino)-1H-pyrazole-3-carboxamide; AM6545, 5-(4-(4-cyanobut-1-yn-1-yl)phenyl)-1-(2,4-dichlorophenyl)- $N$-(1,1dioxidothiomorpholino)-4-methyl-1H-pyrazole-3-carboxamide; $\mathrm{CB}_{1}$, cannabinoid receptor 1 ; FAAH, fatty acid amide hydrolase; FR, fixed ratio; JWH-018, 1-pentyl-3-(1-naphthoyl)indole; MGL, monoacylglycerol lipase; nabilone, 9-nor-9-oxo-3-(1,1-dimethylheptyl)hexahydrocannabinol; rimonabant, 5-(4-chlorophenyl)-1-(2,4-dichloro-phenyl)-4-methyl- $N$-(piperidin-1-yl)-1H-pyrazole-3-carboxamide; SEM, standard error of the mean; $\Delta^{9}$-THC, $\Delta^{9}$ tetrahydrocannabinol; URB597, [3-(3-carbamoylphenyl)phenyl] N-cyclohexylcarbamate. 
Unfortunately, medications have not yet been developed to attenuate these symptoms and more than 300,000 people enter treatment for cannabis use disorder in the United States each year (Substance Abuse and Mental Health Services Administration, Center for Behavioral Health Statistics and Quality, 2014) without the assistance of a Food and Drug Administration-approved pharmacotherapy. To address this treatment gap, researchers have begun to examine the ability of $\mathrm{CB}_{1}$ agonist replacement therapies to suppress cannabis withdrawal symptoms in human subjects (Budney et al., 2007; Levin et al., 2011; Balter et al., 2014; Herrmann et al., 2016). Unfortunately, this effort is handicapped by the difficulty of conducting studies of cannabis withdrawal in laboratory animals.

One preclinical approach that has been effective in studying withdrawal from chronic treatment with drugs from several pharmacological classes, including cannabinoids, is antagonist drug discrimination. Based upon the standard drug discrimination assay in which a subject is trained to respond differentially following the administration of a training drug dose or its vehicle (Glennon and Young, 2011; McMahon, 2015), drug discrimination work to study withdrawal is conducted in subjects chronically treated with an agonist and trained to discriminate the interoceptive effects produced by an injection of an antagonist from those of its vehicle. Presumably, the subject reports the interoceptive effects associated with the immediate displacement of the agonist from its target receptors which also may provoke behavioral signs of withdrawal. Furthermore, the ability of abruptly discontinuing chronic agonist treatment to mimic the discriminative-stimulus effects of the antagonist in a time-dependent manner provides strong evidence to support this presumption.

Previous applications of this paradigm have confirmed that antagonist discrimination can be an effective surrogate for withdrawal. For example, Gellert and Holtzman (1979) showed that the discriminative-stimulus effects of the opioid antagonist naltrexone corresponded well with weight loss in rats that were chronically treated with morphine. Subsequently, France and Woods (1989) extended naltrexone drug discrimination studies to nonhuman primates receiving daily injections of morphine and detailed the behavioral effects and binding affinities of a variety of opioid antagonists and agonists (France et al., 1990, 1995).

The pioneering work with opioid antagonist discrimination has been extended into studies of benzodiazepine dependence in chlordiazepoxide-treated monkeys that were trained to discriminate flumazenil (France and Gerak, 1997) and, more recently, studies of $\mathrm{CB}_{1}$ dependence in $\Delta^{9}$-tetrahydrocannabinol ( $\Delta^{9}$-THC)-treated monkeys that were trained to discriminate the $\mathrm{CB}_{1}$ inverse agonist/antagonist 5-(4-chlorophenyl)-1(2,4-dichloro-phenyl)-4-methyl- $N$-(piperidin-1-yl)- $1 H$-pyrazole3 -carboxamide (rimonabant) (Stewart and McMahon, 2010). Results of the latter studies showed that rimonabant was dosedependently discriminated from vehicle during chronic $\Delta^{9}$-THC treatment and that these effects were attenuated by $\Delta^{9}$-THC and other $\mathrm{CB}_{1}$ agonists. As well, abrupt discontinuation of $\Delta^{9}$-THC treatment increased rimonabant-lever responding in a time-dependent manner. Withdrawal measures including changes in heart rate and home cage activity were reported to generally track data from rimonabant-discrimination studies (Stewart and McMahon, 2010; see also Wilkerson et al., 2019).
In addition, head shaking, previously associated with rimonabant administration in $\Delta^{9}$-THC-treated mice (Cook et al., 1998), was observed following both rimonabant administration and $\Delta^{9}$-THC discontinuation and was attenuated by $\mathrm{CB}_{1}$ agonists. These findings provide intriguing parallels to data from previous antagonist discrimination studies, and suggest that such studies may be similarly useful in identifying novel medications for the management of symptoms associated with cannabis withdrawal.

The purpose of the present studies was to extend the work of Stewart and McMahon (2010) in two ways. First, the utility of the rimonabant discrimination procedure for characterizing different types of $\mathrm{CB}_{1}$ antagonist actions was assessed by determining the effects of $\mathrm{CB}_{1}$ neutral antagonists [5-(4alkylphenyl)-1-(2,4-dichlorophenyl)-4-methyl- $N$-(piperidin-1yl)-1H-pyrazole-3-carboxamide (AM4113), 5-(4-alkylphenyl)1-(2,4-dichlorophenyl)-4-methyl- $N$-(morpholino)-1 $H$-pyrazole3-carboxamide (AM6527), and 5-(4-(4-cyanobut-1-yn-1-yl)phenyl)1-(2,4-dichlorophenyl)- $N$-(1,1-dioxidothiomorpholino)-4-methyl$1 H$-pyrazole-3-carboxamide (AM6545)] in squirrel monkeys treated daily with the long-acting $\mathrm{CB}_{1}$ agonist $9 \beta$-hydroxy3-(1-hexyl-cyclobut-1-yl)-hexahydrocannabinol (AM2389) and trained to discriminate rimonabant from vehicle. Second, different types of cannabinergic drugs were compared for their ability to attenuate the rimonabant-like effects of discontinuing AM2389 treatment. These included the phytocannabinoid $\Delta^{9}$-THC, synthetic $\mathrm{CB}_{1}$ agonists 9-nor-9-oxo-3(1,1-dimethylheptyl)hexahydrocannabinol (nabilone) and $9 \beta$ (hydroxymethyl)-3-(1-adamantyl)-hexahydrocannabinol (AM4054), and the K2/Spice compound 1-pentyl-3-(1-naphthoyl)indole (JWH-018). In addition, effects of the fatty acid amide hydrolase (FAAH)-selective inhibitors 5-(4-hydroxyphenyl) pentanesulfonyl fluoride (AM3506) and [3-(3-carbamoylphenyl)phenyl] $N$-cyclohexylcarbamate (URB597), and nonselective FAAH/monoacylglycerol lipase (MGL) inhibitor 3cyanophenyl 4-benzylpiperidine-1-carboxylate (AM4302), were examined to determine whether elevating levels of the endocannabinoids anandamide and/or 2-arachidonoylglycerol also might attenuate the rimonabant-like effects of discontinuing agonist treatment. These substitution tests were designed to further appraise the $\mathrm{CB}_{1}$ antagonist drug discrimination assay as a means to identify candidate medications that might be useful as agonist replacement therapies for cannabis use disorders.

\section{Materials and Methods}

\section{Subjects}

Four adult male squirrel monkeys (Saimiri sciureus) were individually housed in a temperature- and humidity-controlled vivarium with a 12-hour light/dark cycle (7 AM-7 PM) in a facility licensed by the US Department of Agriculture. All procedures involving the use of experimental subjects in the present studies were approved by the Institutional Animal Care and Use Committee at McLean Hospital and were in accord with the Guidelines for the Care and Use of Mammals in Neuroscience and Behavioral Research (National Research Council, 2011). Throughout the present studies, all subjects had unlimited access to water in their home cage and were maintained at approximate free-feeding weights by post-session feedings of a nutritionally balanced diet of high protein primate chow (Purina Monkey Chow, St. Louis, MO). In addition, fresh fruit and environmental enrichment were provided daily. All subjects had previously served in studies of other behaviorally active drugs (e.g., cannabinoids, opioids, 
and stimulants) but were drug free for at least 6 months prior to the present studies. Each subject was implanted with an intravenous (i.v.) catheter using sterile techniques under isoflurane anesthesia (Herd et al., 1969). One end of a round-tip silicone catheter (inner diameter, $0.6 \mathrm{~mm}$; outer diameter, $1.2 \mathrm{~mm}$; Access Technologies, Skokie, IL) was inserted into a femoral vein and the other end was connected to a subdermal vascular access port (Access Technologies) placed in the monkey's midlumbar area.

\section{Apparatus}

During experimental sessions, subjects were seated in a Plexiglass chair (Kangas et al., 2013) in a ventilated sound- and light-attenuating chamber. Two response levers were positioned $6 \mathrm{~cm}$ left and right of the center front panel of the chair. Each lever-press with a force of at least $0.25 \mathrm{~N}$ closed a microswitch, produced an audible relay click, and was recorded as a response. Red stimulus lights were mounted behind the front panel of the chair and $10 \mathrm{~cm}$ above each response lever. Before each session, a shaved portion of the subject's tail was coated with electrode paste and placed under brass electrodes for the delivery of brief, low-intensity current (200 millisecond; $3 \mathrm{~mA}$ ). Experimental events and data collection were controlled by Med Associates (St. Albans, VT) interfacing equipment and operating software.

\section{Behavioral Procedure}

Rimonabant Discrimination. Subjects were given an intramuscular (i.m.) injection once daily of the potent and long-acting cannabinoid agonist AM2389 (Nikas et al., 2010). This $\mathrm{CB}_{1}$ agonist has $\Delta^{9}$-THC-like discriminative-stimulus effects (Kangas et al., 2013) and has been shown to have protracted behavioral effects in both rats and nonhuman primates. For example, the dose of $0.01 \mathrm{mg} / \mathrm{kg}$, administered acutely, was found to have a functional half-life of 17 hour in rats (Järbe et al., 2012) and, in preliminary dose-ranging experiments, produced a disruption of operant behavior that was evident 24 hour after administration in nonhuman primates. Initially, $0.003 \mathrm{mg} / \mathrm{kg}$ AM2389 was given daily; the dose was then increased by a quarter log unit every 5 days until the desired chronic dose was established $(0.01 \mathrm{mg} / \mathrm{kg})$. Thereafter, antagonist drug discrimination training sessions were introduced, and subjects were trained to discriminate i.v. infusions of the cannabinoid inverse agonist/antagonist rimonabant $(0.3 \mathrm{mg} / \mathrm{kg})$ from saline in a two-lever operant procedure. Sessions were conducted Monday-Friday, 3 hours after administration of AM2389. One lever was designated as the rimonabant lever and the other lever was designated as the saline lever. Assignment of rimonabant and saline lever was counterbalanced across subjects. On training days, immediately prior to the session, i.v. rimonabant or saline was administered to the chaired subject. The session began with a 10 minute timeout period during which there were no programmed consequences. Following the timeout period, the first trial began with the illumination of two red stimulus lights above each lever. Subjects were trained to complete 10 consecutive responses (fixed-ratio [FR] 10) on the injection-appropriate (correct) lever to turn off the red stimulus lights associated with delivery of current. Responses on the other (incorrect) lever reset the FR requirement on the correct lever. Current delivery was scheduled in the presence of the red stimulus lights every 10 second until either the FR10 was completed on the correct lever or 40 second elapsed, whichever came first. When the red stimulus lights turned off, a timeout period of 50 seconds began before the start of the next trial. Training sessions consisted of 20 trials. A double-alternation injection schedule of drug-drug-saline-saline across training sessions was employed throughout training, with a third drug or vehicle session programmed intermittently to avoid associations based on the regularity of the double alternation schedule.

\section{Drug Testing}

In test sessions involving i.v. drug administration, the vascular access port was accessed by syringe from inside the experimental chamber via a catheter tubing/Huber needle assembly. Tests for generalization to the training stimulus $(0.3 \mathrm{mg} / \mathrm{kg}$ rimonabant $)$ were conducted only when, in the immediately preceding session and for four of the last five training sessions, the first FR10 was completed on the injection-appropriate lever and overall discriminative performance was at least $90 \%$ accurate. Test sessions occurred no more frequently than twice weekly, with training sessions scheduled on the remaining days of the week. Procedurally, test sessions differed from training sessions in two ways. First, 10 consecutive responses on either lever turned off the stimulus lights previously associated with current delivery and initiated the 50 second timeout. Second, no current deliveries were scheduled during test sessions so as to preclude their possible influence on performance.

Dose- and Time-Related Effects of AM2389. Experiments were conducted to determine if rimonabant-lever responding could be produced by either reducing the daily dose of AM2389 or lengthening the interval between administration of the chronic dose of AM2389 and the test session. The dose-related effects of daily AM2389 were determined by replacing the chronic dose $(0.01 \mathrm{mg} / \mathrm{kg})$ with smaller doses $(0.001-0.003 \mathrm{mg} / \mathrm{kg}) 3$ hour before test sessions. In other test sessions, an in vivo time course was established for AM2389 by administering the chronic dose of $0.01 \mathrm{mg} / \mathrm{kg}$ AM2389 at different intervals preceding the experimental session (6-48 hour). Saline was administered immediately prior to each of these test sessions. In addition, when assessing the effects of withholding the AM2389 dose for 24 and 48 hour, saline was administered 3 hour prior to the test sessions in lieu of AM2389.

Discriminative-Stimulus Effects of Rimonabant and $\mathbf{C B}_{1}$ Neutral Antagonists. Cumulative dosing procedures were used to establish dose-effect functions for the discriminative-stimulus effects of the $\mathrm{CB}_{1}$ inverse agonist/antagonist rimonabant (Landsman et al., 1997; Mato et al., 2002) and the $\mathrm{CB}_{1}$ neutral antagonists AM4113, AM6527, and AM6545 (Sink et al., 2008, 2009; Cluny et al., 2010; Tam et al., 2010). As with training sessions, AM2389 was given 3 hours prior to test sessions. A test session consisted of up to four components of 10 trials, each component beginning with a 10 -minute timeout period. This procedure permitted the study of up to four incremental doses of a drug delivered i.v. at the onset of sequential timeout periods of a single test session (e.g., Spealman, 1985; Lamb et al., 2000; Kangas et al., 2013).

Substitution for AM2389 by $\mathbf{C B}_{1}$ Agonists and Enzyme Inhibitors. To examine the ability of other drugs to substitute for the chronic dose of AM2389, dose-response functions were determined for the cannabinoid agonists $\Delta^{9}$-THC, nabilone, JWH-018, AM4054, the FAAH inhibitors AM3506 and URB597, and the nonselective FAAH/MGL inhibitor AM4302. AM2389 was not given prior to these test sessions. Instead, single dosing procedures were used in which a dose of a test drug was administered i.m. 60 minute prior to the session and evaluated during one component consisting of 20 trials. The pretreatment time and session duration were based on findings from preliminary time course experiments and previously published work in squirrel monkeys (Kangas et al., 2013, 2016; Leonard et al., 2017). The order of drug testing varied among subjects. Doses of each drug were tested in a quasi-random order and experiments with one drug were completed before beginning experiments with the next drug.

\section{Data Analysis}

The two primary dependent measures in these experiments were the distribution of responding across levers, expressed as percent rimonabant-lever responding, and overall response rate. Percent rimonabant-lever responding was calculated by dividing the number of responses on the lever associated with the injection of rimonabant by the total number of responses on both levers (excluding any responses during timeout periods). Response rate was calculated by dividing the total number of responses on both levers by the total session time (excluding all timeout periods). Doses of drugs or 
treatment conditions, e.g., changes in AM2389 daily dose or pretreatment time, were considered to substitute fully for rimonabant when rimonabant-lever responding was $>90 \%$ of all responses and response rates were $>0.2$ responses/s Doses of drugs or treatment conditions were considered to substitute fully for AM2389 when vehicle-lever responding was $>90 \%$ of all responses and response rates were $>0.2$ responses/s.

\section{Drugs}

AM2389, AM3506, AM4054, AM4113, AM4302, AM6527, AM6545, JWH-018, nabilone, and URB597 were synthesized for these studies by the present authors (KV, SOA, SJ, SPN, AM) in the Center for Drug Discovery at Northeastern University (Boston, MA). Rimonabant and $\Delta^{9}$-THC were provided by the National Institute on Drug Abuse Drug Supply Program (Rockville, MD). All drugs were tested in all four subjects whenever possible. AM2389, AM3506, AM4054, JWH-018, nabilone, rimonabant, and $\Delta^{9}$-THC were prepared in a 20:20:60 mixture of 95\% ethanol, Tween-80, and saline. AM4113, AM6527, and AM6545 were prepared in a 30:30:40 vehicle of 95\% ethanol, Tween-80, and saline. AM4302 and URB597 were dissolved in $100 \%$ dimethyl sulfoxide (DMSO). All drug solutions were refrigerated and protected from light. Injections of drug or saline were prepared in volumes of $0.3 \mathrm{ml} / \mathrm{kg}$ body weight or less and administered i.m. in calf or thigh muscle and i.v. through the venous access ports as described above.

\section{Results}

Rimonabant Discrimination. All subjects acquired the rimonabant discrimination in approximately 30-60 sessions. Following acquisition, i.v. injections of the training dose of rimonabant produced an average of $>98 \%$ responding on the rimonabant lever, whereas saline produced an average of $<1 \%$ responding on the rimonabant lever. Control response rates remained constant throughout the study. Subjects responded an average of $3.4 \pm 0.3$ responses/s following the training doses of rimonabant and an average of $2.9 \pm 0.4$ responses/s following saline.
Dose- and Time-Related Effects of AM2389. As shown in the top panel of Fig. 1A, reducing the daily treatment dose of AM2389 produced dose-dependent increases in mean levels of rimonabant-lever responding. Three of the four subjects tested with $0.001 \mathrm{mg} / \mathrm{kg}$ AM2389 responded $>95 \%$ on the rimonabant lever whereas the fourth subject responded exclusively on the saline lever. When tested with $0.0018 \mathrm{mg} / \mathrm{kg}$ AM2389, two subjects responded exclusively on the rimonabant lever, a third subject responded approximately $40 \%$ on the rimonabant lever, and the fourth subject again responded exclusively on the saline lever. After $0.003 \mathrm{mg} / \mathrm{kg}$ AM2389, three subjects responded exclusively on the saline lever whereas the fourth subject responded $30 \%$ on the rimonabant lever. Response rates approximated control values in all AM2389 tests (see Fig. 1A, lower panel). The top panel of Fig. 1B shows the time course of rimonabant-like discriminative-stimulus effects of withholding the chronic dose of $0.01 \mathrm{mg} / \mathrm{kg}$ AM2389 for differing lengths of time. The full time course was captured within 24-hours, with $0 \%$ responding on the rimonabantassociated lever after 6 hours in all subjects, a group average of $58 \%$ responding on the rimonabant-associated lever after 12 hours (derived from a mixed allocation of rimonabant and saline lever responding in all subjects tested), and approximately $99 \%$ and $100 \%$ responding on the rimonabantassociated lever after, respectively, 24 and 48 hours following the last chronic treatment with AM2389. Both average and individual response rates were largely unaffected by treatment condition, remaining generally within control levels throughout these time course determinations (see Fig. 1B, lower panel).

Discriminative-Stimulus Effects of Rimonabant and CB $_{1}$ Neutral Antagonists. Figure 2 presents the mean percent rimonabant-lever responding (upper panels) and response rate (lower panels) following cumulative i.v. doses of rimonabant and $\mathrm{CB}_{1}$ neutral antagonists $\mathrm{AM} 4113$, AM6527, and AM6545. All antagonists produced cumulative dose-related increases in rimonabant-lever responding. The cumulative
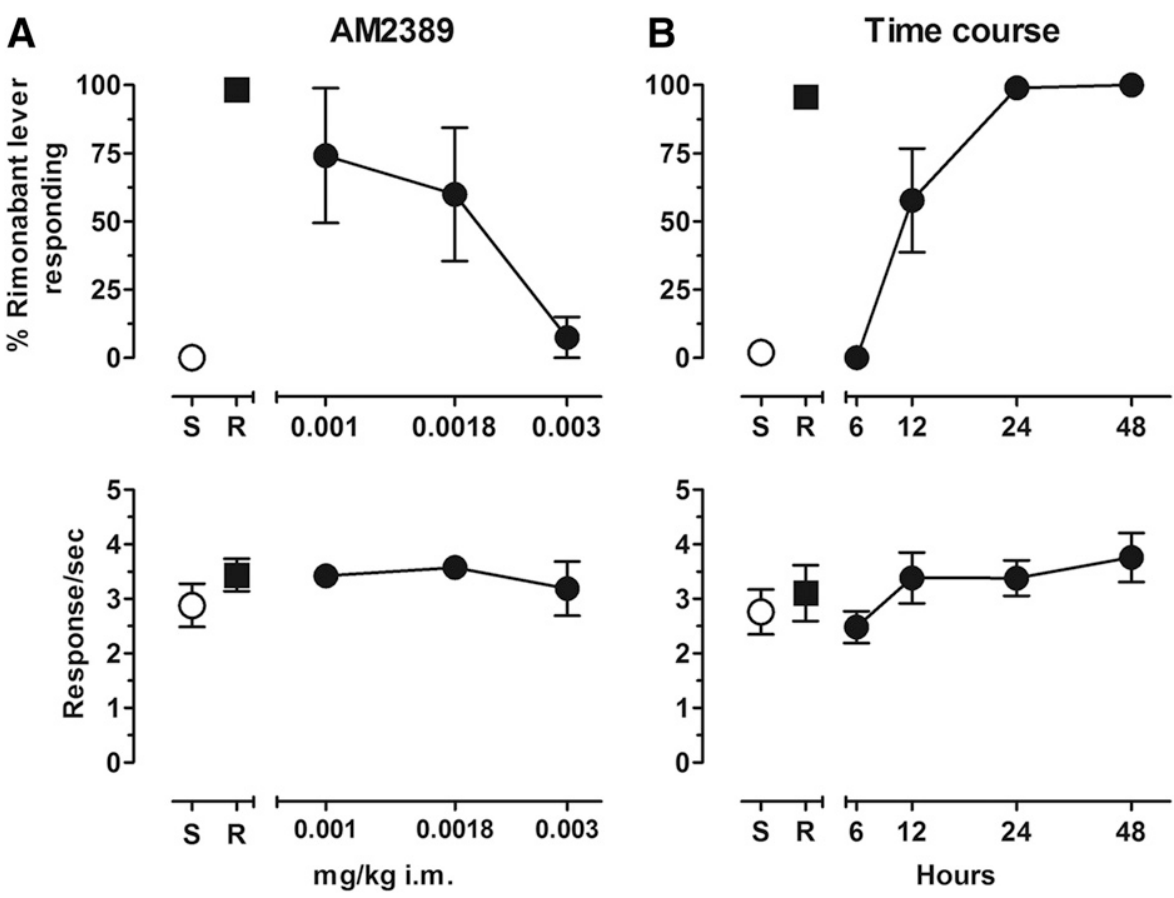

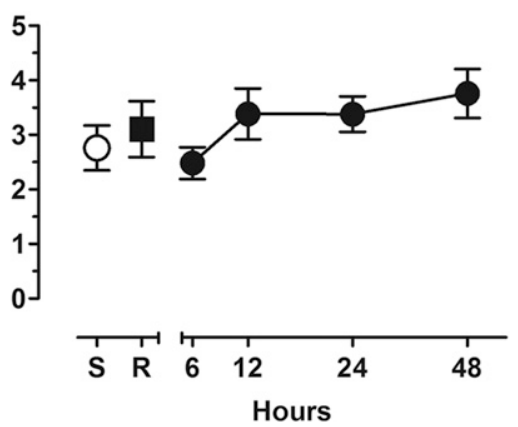

Fig. 1. (A) Dose-effect function for AM2389 administered i.m. $(n=4)$. Abscissae, dose, log scale; ordinate, percent of responses on the rimonabant lever (top panel (A)), response rate (bottom panel (A)). (B) Time course for $0.01 \mathrm{mg} / \mathrm{kg}$ AM2389 administered i.m. (6, 2448 hour $n=4$; 12 hour $n=3$ ). Abscissae, hours after $0.01 \mathrm{mg} / \mathrm{kg}$ AM2389 injection, log scale; ordinate, percent of responses on the rimonabant lever (top panel B), response rate (bottom panel B). Symbols left of abscissae break indicate performance during saline (S) and rimonabant (R) control sessions. Points represent averages ( \pm S.E.M.) for the group of subjects. 

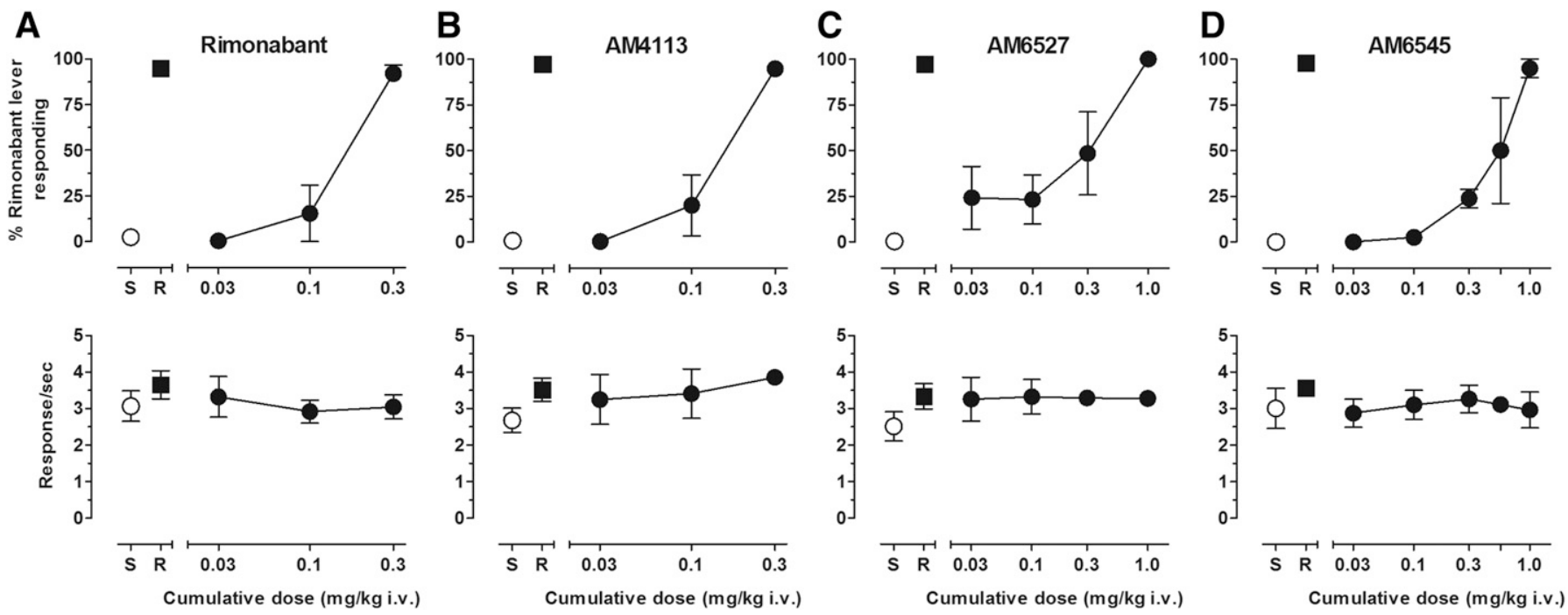

Fig. 2. (A) Dose-effect function for rimonabant administered i.v. $(n=4)$. (B) Dose-effect function for AM4113 administered i.v. $(n=4)$. (C): Dose-effect function for AM6527 administered i.v. (0.03-0.3 mg/kg $n=4,1.0 \mathrm{mg} / \mathrm{kg} n=2$ ). (D) Dose-effect function for AM6545 administered i.v. (0.030.56 mg/kg $n=4,1.0 \mathrm{mg} / \mathrm{kg} n=2$ ). Abscissae, cumulative dose, log scale; ordinate, percent of responses on the rimonabant lever (top panels), response rate (bottom panels). Symbols left of abscissae break indicate performance during saline (S) and rimonabant (R) control sessions. Points represent averages $( \pm$ S.E.M.) for the group of subjects.

dose of $0.3 \mathrm{mg} / \mathrm{kg}$ rimonabant fully substituted for the single $0.3 \mathrm{mg} / \mathrm{kg}$ training dose of rimonabant (Fig. $2 \mathrm{~A}$ ). In addition, all $\mathrm{CB}_{1}$ neutral antagonists fully substituted for the training dose of rimonabant following cumulative doses of $0.3 \mathrm{mg} / \mathrm{kg}$ AM4113 (Fig. 2B), $1.0 \mathrm{mg} / \mathrm{kg}$ AM6527 (Fig. 2C), and $1.0 \mathrm{mg} / \mathrm{kg}$ AM6545 (Fig. 2D). Group average dose-response functions generally reflect data among individual subjects and show that rimonabant and AM4113 produced their effects with similar potency. However, some differences in sensitivity to the effects of AM6527 and AM6545 were observed among subjects. For example, the cumulative dose of $0.3 \mathrm{mg} / \mathrm{kg}$ AM6527 produced $\leq 20 \%$ responding on the rimonabant lever in two subjects but $\geq 84 \%$ responding on the rimonabant lever in the other two subjects. Likewise, two subjects responded exclusively on the saline lever following the cumulative dose of $0.56 \mathrm{mg} / \mathrm{kg}$ AM6545, whereas the other two subjects responded exclusively on the rimonabant lever at that dose. As shown in the bottom panels of Fig. 2, mean response rates were largely unaffected during these test sessions and remained generally within control levels across the range of all antagonist doses tested.

Substitution for AM2389 by $\mathbf{C B}_{1}$ Agonists and Enzyme Inhibitors. Figure 3 shows the effects of a full range of doses of $\mathrm{CB}_{1}$ receptor agonists and enzyme inhibitors tested for their ability to substitute for the chronic dose of AM2389 prior to test sessions. All $\mathrm{CB}_{1}$ receptor agonists produced dose-related decreases in responding on the rimonabant lever, with $>90 \%$ saline-lever responding following administration of $1.0 \mathrm{mg} / \mathrm{kg} \Delta^{9}$-THC (Fig. 3A), $0.1 \mathrm{mg} / \mathrm{kg}$ nabilone (Fig. 3B), and $0.03 \mathrm{mg} / \mathrm{kg} \mathrm{AM} 4054$ (Fig. 3C). Administration of $0.3 \mathrm{mg} / \mathrm{kg}$ JWH-018 produced exclusive saline lever responding in two of the three subjects tested, but exclusive rimonabant lever responding in the third subject (Fig. 3D). The FAAH-selective inhibitor AM3506 produced dose-dependent decreases in responding on the rimonabant lever, with exclusive saline lever responding in two out of the three subjects following administration of $3 \mathrm{mg} / \mathrm{kg}$ and $90 \%$ saline lever responding in the third subject following administration of $5.6 \mathrm{mg} / \mathrm{kg}$
(Fig. 3E). In contrast, doses of the FAAH-selective inhibitor URB597 up to $5.6 \mathrm{mg} / \mathrm{kg}$ or of the nonselective FAAH/MGL inhibitor AM4302 up to $10 \mathrm{mg} / \mathrm{kg}$ failed to reduce responding on the rimonabant lever (Fig. 3, F and G). Response rates following administration of all agonist and enzyme inhibitor doses presented in Fig. 3 were largely unaffected by drug treatments and remained within the range of control values (data not shown).

\section{Discussion}

Findings from the present studies indicate that squirrel monkeys treated daily with the long-acting $\mathrm{CB}_{1}$ agonist AM2389 effectively discriminated the $\mathrm{CB}_{1}$ inverse agonist/ antagonist rimonabant from saline. Discriminative-stimulus effects of rimonabant were stable throughout the present studies and were both dose- and time-dependent. Thus, exclusive rimonabant-lever responding in all subjects could be engendered either by the training dose of rimonabant or by withholding the daily AM2389 treatment for 24 hour, consistent with the long duration of AM2389's $\mathrm{CB}_{1}$ receptormediated action observed in other studies (cf. Järbe et al., 2012). These data provide important corroborative evidence that, in subjects chronically treated with a $\mathrm{CB}_{1}$ agonist, its displacement from $\mathrm{CB}_{1}$ receptors by a $\mathrm{CB}_{1}$ inverse agonist/ antagonist induces interoceptive effects similar to those provoked by the time-dependent reduction in agonist activity following agonist discontinuation.

Previous signal transduction studies showed that, in contrast to $\mathrm{CB}_{1}$ agonists, rimonabant increased cAMP levels in neuronal cell lines in rat and human brain membranes, suggesting that rimonabant served as an inverse agonist/ antagonist ligand at the $\mathrm{CB}_{1}$ receptor (e.g., Felder et al., 1998; Meschler et al., 2000; Mato et al., 2002). However, rimonabant also was reported to decrease basal levels of $\left.{ }^{[5} \mathrm{S}\right] \mathrm{GTP} \gamma \mathrm{S}$ in membranes from both $\mathrm{CB}_{1}$ wild-type and $\mathrm{CB}_{1}$ knockout mice, suggesting that the effects of rimonabant that appear to be due to inverse agonism may occur independently of $\mathrm{CB}_{1}$ receptor 


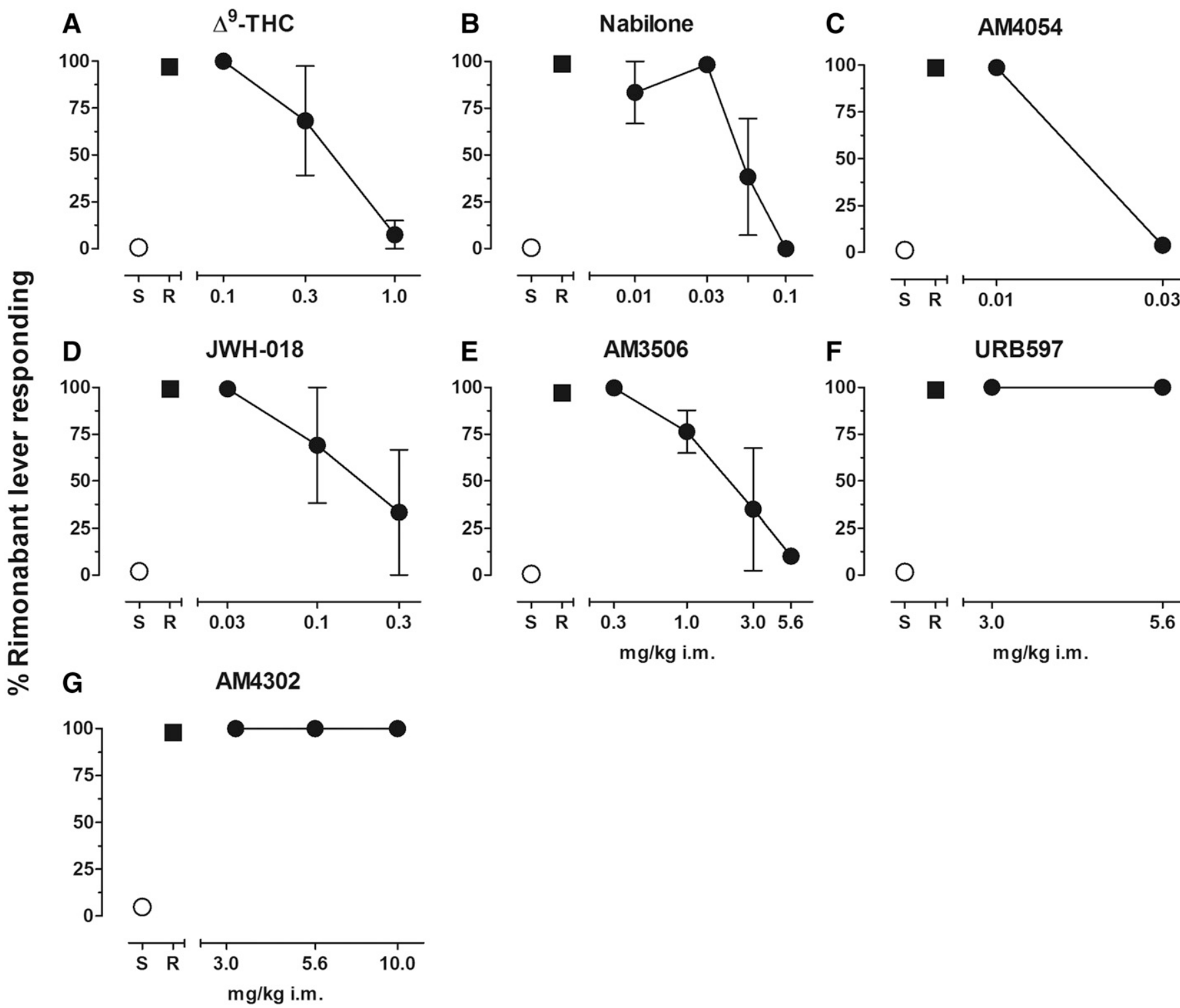

Fig. 3. (A) Dose-effect function for $\Delta^{9}$-THC administered i.m. $(0.1-0.3 \mathrm{mg} / \mathrm{kg} n=3,1.0 \mathrm{mg} / \mathrm{kg} n=2)$. (B) Dose-effect function for nabilone administered i.m. $(n=3)$. (C) Dose-effect function for AM4054 administered i.m. $(n=4)$. (D) Dose-effect function for JWH-018 administered i.m. ( $(n=3)$. (E) Dose-effect function for AM3506 administered i.m. $(0.3-3.0 \mathrm{mg} / \mathrm{kg} n=3,5.6 \mathrm{mg} / \mathrm{kg} n=1)$. (F) Dose-effect function for URB597 administered i.m. ( $n=3)$. (G) Dose-effect function for AM4302 administered i.m. $(n=4)$. Abscissae dose, log scale; ordinate, percent of responses on the rimonabant lever. Symbols left of abscissae break indicate performance during saline (S) and rimonabant (R) control sessions. Points represent averages ( \pm S.E.M.) for the group of subjects.

occupation (Cinar and Szücs, 2009). This latter idea has been supported by more recent studies showing that the inverse agonist-based effects of rimonabant are not blocked by a $\mathrm{CB}_{1}$ agonist or by a $\mathrm{CB}_{1}$ neutral antagonist (e.g., Erdozain et al., 2012). Moreover, Porcu et al. (2018) have reported that micromolar concentrations of rimonabant can inhibit $\mathrm{CB}_{1^{-}}$independent $\mathrm{G} \alpha_{\mathrm{j} / \mathrm{o}}$-type $\mathrm{G}$ proteins, resulting in a receptorindependent block of $G$ protein signaling. Findings such as these raise the possibility that the discriminative-stimulus effects of rimonabant in the present studies may have been independent of its antagonist effects at $\mathrm{CB}_{1}$ receptors. However, several aspects of the present results suggest that it is more likely that the discriminative-stimulus effects of rimonabant were the result of its ability to block the activation of $\mathrm{CB}_{1}$ receptors. First, the stimulus effects of an i.v. injection of rimonabant were reproduced by the discontinuation of $\mathrm{CB}_{1}$ agonist treatment in a time-dependent manner, suggesting the two manipulations acted via a common $\mathrm{CB}_{1}$-mediated mechanism. Second, $\mathrm{CB}_{1}$ receptor agonists were able to dosedependently substitute for AM2389 in reducing responding that would otherwise occur on the rimonabant-associated lever 24 hour after the last injection of AM2389. Third, the discriminative-stimulus effects of rimonabant were fully reproduced by $\mathrm{CB}_{1}$ receptor blockers that, based on their lack of effect on adenylate cyclase activity over a wide range of concentrations and their behavioral profiles of action, are considered to be neutral antagonists. For example, AM4113 and AM6527, which produced dose-related increases in rimonabant-lever responding in the present studies, previously have been shown to produce rimonabant-like antagonism of the behavioral effects of $\mathrm{CB}_{1}$ agonists in rodents and nonhuman primates but, unlike rimonabant, reduce both 
feeding and food reinforced lever responding in rodents without eliciting nausea- and malaise-related behavior (Chambers et al., 2007; Sink et al., 2008, 2009; Kangas et al., 2013). It is interesting that AM6545 also produced rimonabant-like effects in the present study. This ligand which, due to its rapid P-glycoprotein-mediated extrusion from the central nervous system, does not accumulate in high concentration in brain tissue after i.m. or i.p. administration, has been characterized previously as a peripherally-restricted $\mathrm{CB}_{1}$ antagonist (Cluny et al., 2010; Tam et al., 2010). However, the present results imply that brain levels of AM6545 following i.v. administration to nonhuman primates are sufficient to produce rimonabant-like discriminative-stimulus effects. Moreover, AM6545 has been characterized as a neutral antagonist (Cluny et al., 2010; Tam et al., 2010), further supporting the view that the discriminative-stimulus effects of rimonabant in $\mathrm{CB}_{1}$ agonist-treated subjects likely result from its antagonist, rather than inverse agonist, properties.

All $\mathrm{CB}_{1}$ agonists tested in the present studies attenuated the rimonabant-like discriminative stimulus effects of discontinuing AM2389 treatment. To better contextualize their potency under these conditions, Fig. 4 presents the relationship between the effects of the $\mathrm{CB}_{1}$ agonists in the present antagonist drug discrimination studies and their effects in previous agonist drug discrimination studies. $\mathrm{ED}_{50}$ values for attenuating the rimonabant-like effects of discontinuing $\mathrm{CB}_{1}$ agonist treatment were derived from the present data, whereas $\mathrm{ED}_{50}$ values from agonist drug discrimination were derived from previous work in squirrel monkeys discriminating $0.1 \mathrm{mg} / \mathrm{kg} \mathrm{AM} 4054$ from saline (see Kangas et al. (2013) for AM2389, AM4054, and $\Delta^{9}$-THC; values for nabilone, JWH018, and AM3506 are from unpublished studies). As shown, although the studies from which these values are taken were designed and conducted independently, the relationship between $\mathrm{ED}_{50}$ values across $\mathrm{CB}_{1}$ agonists is highly correlated $\left(R^{2}=0.99, P=0.0001\right)$. In addition, $\mathrm{ED}_{50}$ values were

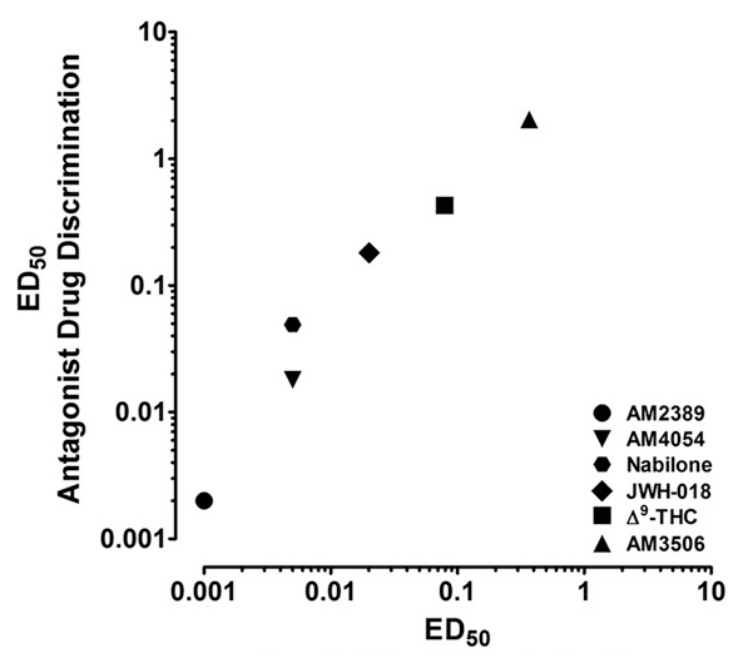

Agonist Drug Discrimination

Fig. 4. Relationship between the $\mathrm{ED}_{50}$ values of $\mathrm{CB}_{1}$ agonists during agonist drug discrimination (abscissa) and antagonist drug discrimination (ordinate). $\mathrm{ED}_{50}$ values from antagonist drug discrimination were derived from the present studies. $\mathrm{ED}_{50}$ values from agonist drug discrimination of AM2389, AM4054, and $\Delta^{9}$-THC were derived from Kangas et al. (2013) and nabilone, JWH-018, and AM3506 were derived from unpublished studies. consistently larger in antagonist drug discrimination, a relationship that is confirmed by linear regression of the data in Fig. 4 yielding a slope of 5.5. These potency differences in the two types of discrimination studies likely reflect a variety of influences that include the choice of training drug dose in $\mathrm{CB}_{1}$ agonist discrimination studies as well as the development of tolerance during chronic treatment in the $\mathrm{CB}_{1}$ antagonist discrimination studies. Regardless, the present findings are highly instructive, indicating that the effectiveness of agonist treatment regimens for cannabis dependence may depend on using sufficiently high doses of the pharmacotherapy.

Like $\mathrm{CB}_{1}$ receptor agonists, the FAAH-selective enzyme inhibitor AM3506 dose-dependently reduced the rimonabantlike discriminative-stimulus effects of withholding daily AM2389 treatment. However, AM3506 also binds CB $_{1}$ receptors, albeit with low affinity $(5.77 \mu \mathrm{mol} / \mathrm{l}$; Godlewski et al., 2010; Bashashati et al., 2012). Thus, it is difficult to determine the extent to which the effects of AM3506 were mediated by enzyme inhibition, direct $\mathrm{CB}_{1}$ receptor activation, or a combination of both. In this regard, neither the nonselective FAAH/MGL inhibitor AM4302 nor the FAAH-selective inhibitor URB597 similarly substituted for AM2389 in precluding rimonabant-lever responding. Although previous work in squirrel monkeys indicates that doses of URB597 and AM4302 studied here are pharmacologically active and that URB597 alone does not produce CB1-like effects (Justinova et al., 2008; Leonard et al., 2017), it remains possible that rimonabant-lever responding might have been attenuated by higher doses of AM4302. For example, Leonard et al. (2017) showed that AM4302, like other nonselective FAAH/MGL inhibitors, is fully capable of producing a $\mathrm{CB}_{1}$ discriminative stimulus in agonist-trained subjects. Based on the potency relationship in the two types of discrimination studies discussed above, considerably higher doses of AM4302 than those tested here may be necessary to reduce rimonabant-lever responding. While this question remains to be answered, the present results highlight the possibility of $\mathrm{CB}_{1}$ receptor agonists for reducing the adverse effects associated with cannabinoid dependence and withdrawal—an agonistreplacement approach used with other drugs of abuse such as heroin or nicotine (reviewed in Sofuoglu and Kosten, 2004).

There are a few important caveats in the present studies that warrant consideration. Although the present findings generally are consistent with previous data from earlier rimonabant discrimination studies (Stewart and McMahon, 2010), head shaking was not observed here, which may represent a difference in phylogenic behavior across primate species (i.e., rhesus vs. squirrel monkey). Moreover, although cardinal features of cannabis dependence, including mood and sleep disturbances following discontinuation, were not quantitatively evaluated in the present studies, there were no obvious signs of withdrawal observed following antagonist administration or agonist discontinuation in any subject. In the absence of such data, any conclusions regarding the presence or absence of dependence and a withdrawal syndrome remains highly speculative. For example, it is possible that the discriminative-stimulus effects of rimonabant in the present studies were not associated with withdrawal signs. Instead, subjects may have been reporting the ongoing effects of chronic $\mathrm{CB}_{1}$ agonist exposure (on the saline-associated lever) versus the absence of those effects (on the antagonistassociated lever). 
In conclusion, notwithstanding the above caveats, the cannabinoid antagonist drug discrimination paradigm provides a useful screening procedure for examining the ability of candidate medications to attenuate or prevent the interoceptive stimuli provoked by $\mathrm{CB}_{1}$ agonist discontinuation. Whether this procedure assays cannabinoid withdrawal is presently less certain. The strength of antagonist discrimination studies of opioid or benzodiazepine dependence was established by correlating findings with established physiologic measures of withdrawal. Future antagonist-discrimination studies of cannabinoid withdrawal similarly would benefit by incorporating the quantitative measurement of physiologic disturbances that are proposed as signs of cannabis dependence in the DSM-5. These measures will likely be subtle and may require specialized recording apparatus to measure movement (actigraphy; see Wilkerson et al., 2019), sleep (electroencephalography), or autonomic function (telemetry). However, documenting the degree of concordance between physiologic disturbances and discriminative behavior is essential to validate the paradigm's construct validity with regard to cannabis withdrawal.

\section{Acknowledgments}

The authors thank Roger Spealman for comments on a previous version of this manuscript.

\section{Authorship Contributions}

Participated in research design: Kangas, Bergman.

Conducted experiments: Zakarian.

Contributed new reagents or analytic tools: Vemuri, Alapafuja, Jiang, Nikas, Makriyannis.

Performed data analysis: Kangas, Zakarian.

Wrote or contributed to the writing of the manuscript: Kangas, Zakarian, Bergman.

\section{References}

American Psychiatric Association (2013) Diagnostic and Statistical Manual of Menta Disorders, 5th ed, American Psychiatric Publishing, Arlington, TX.

Balter RE, Cooper ZD, and Haney M (2014) Novel pharmacologic approaches to treating cannabis use disorder. Curr Addict Rep 1:137-143.

Bashashati M, Storr MA, Nikas SP, Wood JT, Godlewski G, Liu J, Ho W, Keenan CM, Zhang H, Alapafuja SO, et al. (2012) Inhibiting fatty acid amide hydrolase normalizes endotoxin-induced enhanced gastrointestinal motility in mice. $\mathrm{Br}$ $J$ Pharmacol 165:1556-1571.

Budney AJ and Hughes JR (2006) The cannabis withdrawal syndrome. Curr Opin Psychiatry 19.233-238.

Budney AJ, Vandrey RG, Hughes JR, Moore BA, and Bahrenburg B (2007) Oral delta-9-tetrahydrocannabinol suppresses cannabis withdrawal symptoms. Drug Alcohol Depend 86:22-29.

Chambers AP, Vemuri VK, Peng Y, Wood JT, Olszewska T, Pittman QJ, Makriyannis $\mathrm{A}$, and Sharkey KA (2007) A neutral $\mathrm{CB}_{1}$ receptor antagonist reduces weight gain in rat. Am J Physiol Regul Integr Comp Physiol 293:R2185-R2193.

Cinar R and Szücs M (2009) $\mathrm{CB}_{1}$ receptor-independent actions of SR141716 on G-protein signaling: coapplication with the $\mu$-opioid agonist Tyr-D-Ala-Gly-(NMe) Phe-Gly-ol unmasks novel, pertussis toxin-insensitive opioid signaling in $\mu$-opioid receptor-Chinese hamster ovary cells. J Pharmacol Exp Ther 330:567-574.

Cluny NL, Vemuri VK, Chambers AP, Limebeer CL, Bedard H, Wood JT, Lutz B, Zimmer A, Parker LA, Makriyannis A, et al. (2010) A novel peripherally restricted cannabinoid receptor antagonist, AM6545, reduces food intake and body weight, but does not cause malaise, in rodents. Br J Pharmacol 161:629-642.

Cook SA, Lowe JA, and Martin BR (1998) CB1 receptor antagonist precipitates withdrawal in mice exposed to $\Delta^{9}$-tetrahydrocannabinol. J Pharmacol Exp Ther 285:1150-1156.

Erdozain AM, Diez-Alarcia R, Meana JJ, and Callado LF (2012) The inverse agonist effect of rimonabant on $\mathrm{G}$ protein activation is not mediated by the cannabinoid CB1 receptor: evidence from postmortem human brain. Biochem Pharmacol 83 260-268.

Felder CC, Joyce KE, Briley EM, Glass M, Mackie KP, Fahey KJ, Cullinan GJ, Hunden DC, Johnson DW, Chaney MO, et al. (1998) LY320135, a novel cannabinoid CB1 receptor antagonist, unmasks coupling of the CB1 receptor to stimulation of cAMP accumulation. J Pharmacol Exp Ther 284:291-297.

France CP, de Costa BR, Jacobson AE, Rice KC, and Woods JH (1990) Apparent affinity of opioid antagonists in morphine-treated rhesus monkeys discriminating between saline and naltrexone. J Pharmacol Exp Ther 252:600-604.
France CP and Gerak LR (1997) Discriminative stimulus effects of flumazenil in rhesus monkeys treated chronically with chlordiazepoxide. Pharmacol Biochem Behav 56:447-455.

France CP, Gerak LR, Flynn D, Winger GD, Medzihradsky F, Bagley JR, Brockunier LL, and Woods JH (1995) Behavioral effects and receptor binding affinities of fentanyl derivatives in rhesus monkeys. J Pharmacol Exp Ther 274: $17-28$

France CP and Woods JH (1989) Discriminative stimulus effects of naltrexone in morphine-treated rhesus monkeys. J Pharmacol Exp Ther 250:937-943.

Gellert VF and Holtzman SG (1979) Discriminative stimulus effects of naltrexone in the morphine-dependent rat. J Pharmacol Exp Ther 211:596-605.

Glennon RA and Young R (2011) Drug Discrimination: Applications to Medicinal Chemistry and Drug Studies, John Wiley \& Sons, Malden, MA.

Godlewski G, Alapafuja SO, Bátkai S, Nikas SP, Cinar R, Offertáler L, Osei-Hyiaman D, Liu J, Mukhopadhyay B, Harvey-White J, et al. (2010) Inhibitor of fatty acid amide hydrolase normalizes cardiovascular function in hypertension without adverse metabolic effects. Chem Biol 17:1256-1266.

Herd JA, Morse WH, Kelleher RT, and Jones LG (1969) Arterial hypertension in the squirrel monkey during behavioral experiments. Am J Physiol 217:24-29.

Herrmann ES, Cooper ZD, Bedi G, Ramesh D, Reed SC, Comer SD, Foltin RW, and Haney M (2016) Effects of zolpidem alone and in combination with nabilone on cannabis withdrawal and a laboratory model of relapse in cannabis users. Psychopharmacology (Berl) 233:2469-2478.

Järbe TUC, Tai S, LeMay BJ, Nikas SP, Shukla VG, Zvonok A, and Makriyannis A (2012) AM2389, a high-affinity, in vivo potent $\mathrm{CB}_{1}$-receptor-selective cannabinergic ligand as evidenced by drug discrimination in rats and hypothermia testing in mice. Psychopharmacology (Berl) 220:417-426.

Justinova Z, Mangieri RA, Bortolato M, Chefer SI, Mukhin AG, Clapper JR, King AR, Redhi GH, Yasar S, Piomelli D, et al. (2008) Fatty acid amide hydrolase inhibition heightens anandamide signaling without producing reinforcing effects in primates. Biol Psychiatry 64:930-937.

Kangas BD, Delatte MS, Vemuri VK, Thakur GA, Nikas SP, Subramanian KV, Shukla VG, Makriyannis A, and Bergman J (2013) Cannabinoid discrimination and antagonism by $\mathrm{CB}_{1}$ neutral and inverse agonist antagonists. $J$ Pharmacol Exp Ther 344:561-567.

Kangas BD, Leonard MZ, Shukla VG, Alapafuja SO, Nikas SP, Makriyannis A, and Bergman J (2016) Comparisons of $\Delta^{9}$-tetrahydrocannabinol and anandamide on a battery of cognition-related behavior in nonhuman primates. $J$ Pharmacol Exp Ther 357:125-133.

Lamb RJ, Järbe TUC, Makriyannis A, Lin S, and Goutopoulos A (2000) Effects of $\Delta 9$ tetrahydrocannabinol, $(R)$-methanandamide, SR 141716 , and $d$-amphetamine before and during daily $\Delta 9$-tetrahydrocannabinol dosing. Eur $J$ Pharmacol 398: $251-258$.

Landsman RS, Burkey TH, Consroe P, Roeske WR, and Yamamura HI (1997) SR141716A is an inverse agonist at the human cannabinoid $\mathrm{CB}_{1}$ receptor. Eur J Pharmacol 334:R1-R2.

Leonard MZ, Alapafuja SO, Ji L, Shukla VG, Liu Y, Nikas SP, Makriyannis A, Bergman J, and Kangas BD (2017) Cannabinoid $\mathrm{CB}_{1}$ discrimination: effects of endocannabinoids and catabolic enzyme inhibitors. J Pharmacol Exp Ther 363: 314-323.

Levin FR, Mariani JJ, Brooks DJ, Pavlicova M, Cheng W, and Nunes EV (2011) Dronabinol for the treatment of cannabis dependence: a randomized, double-blind, placebo-controlled trial. Drug Alcohol Depend 116:142-150.

Mato S, Pazos A, and Valdizán EM (2002) Cannabinoid receptor antagonism and inverse agonism in response to SR141716A on cAMP production in human and rat brain. Eur J Pharmacol 443:43-46.

McMahon LR (2015) The rise (and fall?) of drug discrimination research. Drug Alcohol Depend 151:284-288.

Meschler JP, Kraichely DM, Wilken GH, and Howlett AC (2000) Inverse agonist properties of $N$-(piperidin-1-yl)-5-(4-chlorophenyl)-1-(2, 4-dichlorophenyl)-4methyl-1H-pyrazole-3-carboxamide $\mathrm{HCl}$ (SR141716A) and 1-(2-chlorophenyl)4-cyano-5-(4-methoxyphenyl)-1H-pyrazole-3-carboxylic acid phenylamide (CP-272871) for the $\mathrm{CB}_{1}$ cannabinoid receptor. Biochem Pharmacol 60:1315-1323.

National Research Council (2011) Guide for the Care and Use of Laboratory Animals, National Academies Press (US), Washington, DC.

Nikas SP, Alapafuja SO, Papanastasiou I, Paronis CA, Shukla VG, Papahatjis DP Bowman AL, Halikhedkar A, Han X, and Makriyannis A (2010) Novel 1', $1^{\prime}$ chain substituted hexahydrocannabinols: $9 \beta$-hydroxy-3-(1-hexyl-cyclobut-1-yl)hexahydrocannabinol (AM2389) a highly potent cannabinoid receptor 1 (CB1) agonist. $J$ Med Chem 53:6996-7010.

Porcu A, Melis M, Turecek R, Ullrich C, Mocci I, Bettler B, Gessa GL, and Castelli MP (2018) Rimonabant, a potent CB1 cannabinoid receptor antagonist, is a $\mathrm{G} \alpha_{\mathrm{i} / \mathrm{o}}$ protein inhibitor. Neuropharmacology 133:107-120.

Schlienz NJ, Budney AJ, Lee DC, and Vandrey R (2017) Cannabis withdrawal: a review of neurobiological mechanisms and sex differences. Curr Addict Rep 4: $75-81$.

Sink KS, McLaughlin PJ, Wood JA, Brown C, Fan P, Vemuri VK, Peng Y, Olszewska T, Thakur GA, Makriyannis A, et al. (2008) The novel cannabinoid $\mathrm{CB}_{1}$ receptor neutral antagonist AM4113 suppresses food intake and foodreinforced behavior but does not induce signs of nausea in rats [published correction appears in Neuropsychopharmacology (2008) 33:1776]. Neuropsychopharmacology 33:946-955.

Sink KS, Vemuri VK, Wood J, Makriyannis A, and Salamone JD (2009) Oral bioavailability of the novel cannabinoid CB1 antagonist AM6527: effects on foodreinforced behavior and comparisons with AM4113. Pharmacol Biochem Behav 91 303-306.

Sofuoglu M and Kosten TR (2004) Pharmacologic management of relapse prevention in addictive disorders. Psychiatr Clin North Am 27:627-648.

Spealman RD (1985) Discriminative-stimulus effects of midazolam in squirrel monkeys: comparison with other drugs and antagonism by Ro 15-1788. J Pharmacol Exp Ther 235:456-462. 
Stewart JL and McMahon LR (2010) Rimonabant-induced $\Delta^{9}$-tetrahydrocannabinol withdrawal in rhesus monkeys: discriminative stimulus effects and other withdrawal signs. J Pharmacol Exp Ther 334:347-356.

Substance Abuse and Mental Health Services Administration (2014) Treatment Episode Data Set (TEDS): 2002-2012. National Admissions to Substance Abuse Treatment Services, BHSIS Series S-71, HHS Publication No. (SMA) 14-4850, Center for Behavioral Health Statistics and Quality, Substance Abuse and Mental Health Services Administration, Rockville, MD.

Tam J, Vemuri VK, Liu J, Bátkai S, Mukhopadhyay B, Godlewski G, Osei-Hyiaman D, Ohnuma S, Ambudkar SV, Pickel J, et al. (2010) Peripheral CB1 cannabinoid receptor blockade improves cardiometabolic risk in mouse models of obesity. J Clin Invest 120:2953-2966.

Wilkerson JL, Schulze DR, and McMahon LR (2019) Tolerance and dependence to $\Delta^{9}$ tetrahydrocannabinol in rhesus monkeys: activity assessments. PLoS One 14: e0209947.

Address correspondence to: Dr. Brian D. Kangas, Harvard Medical School, Behavioral Biology Program, McLean Hospital, 115 Mill Street, Belmont, MA 02478. E-mail: bkangas@mclean.harvard.edu 